\title{
Intestinal microbiome and its potential functions in bighead carp (Aristichthys nobilis) under different feeding strategies
}

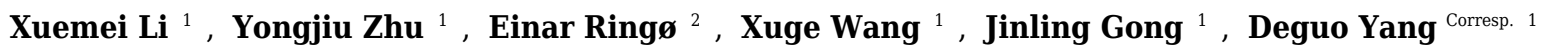 \\ ${ }^{1}$ Key Laboratory of Freshwater Biodiversity Conservation, Ministry of Agriculture of China, Yangtze River Fisheries Research Institute, Chinese Academy of \\ Fishery Sciences, Wuhan, China \\ ${ }^{2}$ Norwegian College of Fishery Science, Faculty of Biosciences, Fisheries and Economics, UiT The Arctic University of Norway, Tromsø, Norway \\ Corresponding Author: Deguo Yang \\ Email address: yangdg@yfi.ac.cn
}

Bighead carps (Aristichthys nobilis) were divided into four groups with different feeding strategies: group A, nature live food only (fertiliser only, $200 \mathrm{~g}$ urea $+160 \mathrm{~g}$ ethylamine phosphate $+250 \mathrm{~g}$ Huangjintai bio-fertiliser); group $B$, nature live food $+1 / 2$ formulated feed; group C, nature live food + formulated feed; and group D, formulated feed only. The intestinal microbiomes of the different groups were compared through the Illumina MiSeq sequencing of the bacterial 16S rRNA gene. The specific growth rate (SGR), survival and blood biochemical factors of the fish were also investigated. Results showed that feeding treatment influenced the intestinal communities in the fish. In specific, more bacterial phyla dominated in groups $A$ and $B$ (phyla Bacteroidetes, Fusobacteria, Firmicutes and Proteobacteria in group A, phyla Proteobacteria and Fusobacteria in group B) than in groups $C$ and $D$ (phylum Proteobacteria). The diversity was also lower in groups $C$ and $D$ than in groups A and B. Unweighted pair-group method analysis revealed a clear difference in intestinal microbiota among the different feeding treatments. No difference in survival rate was found among the treatment groups, but the SGR was significantly higher $(P<0.01)$ in groups $B, C$ and $D$ than in group $A$. Functional analysis showed that the intestinal bacteria correlated with fish glucose metabolism in group A but with lipid metabolic activity in groups $B, C$ and D. In summary, the intestinal microbiomes and their potential functions vary in bighead carp under different feeding treatments. This study provides new insights into the gut microbiomes of filter-feeding and formulated diet-fed fish. 
2 Intestinal microbiome and its potential functions in bighead carp (Aristichthys

3 nobilis) under different feeding strategies

4

5 Xuemei $\mathrm{Li}^{1}$, Yongjiu Zhu ${ }^{1}$, Einar Ringø ${ }^{2}$, Xuge Wang ${ }^{1}$, Jinling Gong, Deguo Yang, ${ }^{1}$,

6

$7{ }^{1}$ Key Laboratory of Freshwater Biodiversity Conservation, Ministry of Agriculture of China,

8 Yangtze River Fisheries Research Institute, Chinese Academy of Fishery Sciences, Wuhan,

9 China.

$10{ }^{2}$ Norwegian College of Fishery Science, Faculty of Biosciences, Fisheries and Economics, UiT

11 The Arctic University of Norway, Tromsø, Norway.

12

13 * Author to whom correspondence should be addressed: Deguo Yang, e-mail: yangdg@yfi.ac.cn 
16

17

18

\section{Abstract}

Bighead carps (Aristichthys nobilis) were divided into four groups with different feeding strategies: group A, nature live food only (fertiliser only, $200 \mathrm{~g}$ urea $+160 \mathrm{~g}$ ethylamine phosphate +250 g Huangjintai bio-fertiliser); group B, nature live food $+1 / 2$ formulated feed; group C, nature live food + formulated feed; and group D, formulated feed only. The intestinal microbiomes of the different groups were compared through the Illumina MiSeq sequencing of the bacterial 16S rRNA gene. The specific growth rate (SGR), survival and blood biochemical factors of the fish were also investigated. Results showed that feeding treatment influenced the intestinal communities in the fish. In specific, more bacterial phyla dominated in groups A and B (phyla Bacteroidetes, Fusobacteria, Firmicutes and Proteobacteria in group A, phyla Proteobacteria and Fusobacteria in group B) than in groups C and D (phylum Proteobacteria). The diversity was also lower in groups C and D than in groups A and B. Unweighted pair-group method analysis revealed a clear difference in intestinal microbiota among the different feeding treatments. No difference in survival rate was found among the treatment groups, but the SGR was significantly higher $(P<0.01)$ in groups $\mathrm{B}, \mathrm{C}$ and $\mathrm{D}$ than in group A. Functional analysis showed that the intestinal bacteria correlated with fish glucose metabolism in group A but with lipid metabolic activity in groups B, C and D. In summary, the intestinal microbiomes and their potential functions vary in bighead carp under different feeding treatments. This study provides new insights into the gut microbiomes of filter-feeding and formulated diet-fed fish. 
39 The gut microbiota of vertebrates, including fish, contributes to nutrition, immunity and 40 development of the host (Ley et al., 2008; Ray et al., 2012; Dinan \& Cryan, 2017; Blum, 2017).

41 Approximately 34,000 fish species have been identified (FishBase, 2017), and they are important

42 to understand physiology, ecology and natural history of vertebrates (Wong \& Rawls, 2012;

43 Tarnecki et al., 2017). Microorganisms from water and food can adhere and colonise the fish gut,

44 and an imbalanced fish gut microbiota can alter the immune regulatory functions of the gut and contribute to disease manifestation (Pérez et al., 2010; Ghanbari et al., 2015). Many factors, such as species, age, developmental stage, geographic location, gender, environmental factors, the individual genetics of fish can modulate the gut microbiota composition (Nayak, 2010; Li et al., 2012; 2013; 2016; Ringø et al., 2016). In addition, diet, including dietary replacement of fishmeal modulate the gut bacterial community in fish (Merrifield et al., 2011; Ye et al., 2014; Baldo et al., 2015; Estruch et al., 2015; Eichmiller et al., 2016; Ringø et al., 2016; Zhou et al., 2017). However, less information is available about differences in the gut microbiomes of fish species fed live food or artificial feed (Savas et al., 2005; Ni et al., 2014). Ni et al. (2014) revealed that the gut microbiota of grass carp (Ctenopharyngodon idella) was modulated by ryegrass (Lolium perenne) or commercial feed, and this modulation help to digest otherwise undigested dietary polysaccharose to achieve nutritional and physiological homeostasis.

In China, bighead carp (Aristichthys nobilis), silver carp (Hypophthalmichthys molitrix), grass carp and black carp (Mylopharyngodon piceus) are the major carp species (Yu et al., 2010). Following the successful breeding of these species during the late 1950s (Zhong et al., 1965),

bighead carp has become one of the most intensively exploited fish species in aquaculture, with 
60 an annual global production of over ten million tons in 2015 and China is the main producer

61 (FAO, 2015). As filter feeders, bighead carp preferentially consumes zooplankton, but also

62 ingests phytoplankton and detritus, and they are also used as a potential biological control agent

63 to improve water quality and increase fish production in culture ponds (Lazareva et al., 1977;

64 Burke et al., 1986; Xie \& Liu, 1987; Conover et al., 2007). With the increasing demand of

65 bighead carp for consumption, pond models with a high density of carp has received

66 considerable attention (Mi et al., 2016). Moreover, feeding bighead carp formulated feed to

67 increase farm yield has become popular and acceptable (Huang \& Pan, 2013; Mi et al., 2016).

68 Considering the influence of diet on fish gut bacterial community, it is of interest to extend the

69 knowledge of bighead carp gut microbiome and their potential metabolic function when the fish

70 is fed natural live food or formulated feed.

71 The aim of this study was evaluate 1) how the intestinal microbiome structure is modulated by

72 different feeding regimes, filter-feeding and formulated diet; 2) and what's the relationship

73 between intestinal microbiome and metabolic functions of bighead carp. The results will improve

74 our understanding of the gut microbiome of filter-feeding and feeding formulated diet fish. 


\section{MATERIALS AND METHODS}

\section{Experimental designs}

78 The experiment was conducted in 12 rectangular enclosure (length $9 \mathrm{~m} \times$ width $6 \mathrm{~m} \times$ height

$792.5 \mathrm{~m})$ in earth ponds $\left(2666.4 \mathrm{~m}^{2}\right)$ at Yaowan fish farming base $(30.16 \mathrm{~N}, 112.18 \mathrm{E})$ in Yangtze

80 River Fisheries Research Institute in Jingzhou City, China. Four different pond management

81 systems, triplicate ponds, were used. Group A (nature live food only): fertilised ponds to obtain

82 zooplankton; cladocera, copepod and rotifer, which were identified in lab according to Jiang \&

83 Du (1979), Shen (1979) and Wang (1961), group B (nature live food $+1 / 2$ formulated feed):

84 fertilised ponds in which bighead carp were fed $1 \%-1.5 \%$ of the body weight (BW) with

85 formulated feed, group C (nature live food + formulated feed): fertilised ponds where fish were

86 fed $2 \%-3 \%$ of the BW with formulated feed and group D (only formulated feed): fish were fed

$872 \%-3 \%$ of the BW with formulated feed.

\section{Pond preparation and management}

All ponds were drained, renovated and sterilised with Lime $(\mathrm{CaO})$ prior to the experiment. Each

pond was filled with well water to $50 \mathrm{~cm}$ and treated with compound fertiliser $(200 \mathrm{~g}$ urea +

$160 \mathrm{~g}$ ethylamine phosphate $+250 \mathrm{~g}$ Huangjintai bio-fertiliser (made of fish protein, dairy

products, astragalan and functional peptides, Hubei Daming Aquatic Science and Technology

Co., Ltd., Hubei) for one week before experimental start. This was done to culture natural live

food for bighead carp. Thereafter, the water level was increased up to $160 \mathrm{~cm}$. The fertiliser was

used twice every week during the experiment in pond A, B and C. Commercially formulated 
$97 \mathrm{C}$ and $\mathrm{D}$. The biochemical composition of the formulated feed was; crude protein $\geq 34.0 \%$, crude

98 lipid $\geq 3.0 \%$, lysine $\geq 1.4 \%$, total phosphorus $\geq 1.0 \%$, crude ash $\leq 15.0 \%$, crude fiber $\leq 12.0 \%$,

99 calcium $=1.0 \%-4.0 \%$ and moisture $\leq 12.0 \%$.

100 Fish were transferred from Hubei Daming Aquatic Science and Technology Co., Ltd in

101 Jingzhou City to the Yaowan fish farming base. 192 fish with initial BW of 906.7 $\pm 102.4 \mathrm{~g}$ and

102 body length (BL) of $37.6 \pm 2.0 \mathrm{~cm}$ were randomly distributed to the ponds, 16 fish per pond,

103 where they were fed formulated diet at a rate of $2 \%-3 \%$ of biomass twice a day $(9: 00$ and

104 16:00). Each pond was equipped with one nanodisk to ensure adequate oxygen level. The

experiment was carried out from April 2014 to September 2014, and the main environmental

factors of the ponds are displayed in Table S1.

107

108

109

110

111

112

113

114

115

116

117

\section{Sample collection and pre-processing}

One hundred and eighty days after the experimental start, fish were captured with falling nets in order to avoid additional stress responses. The falling nets were used twice in each pond, and one or two fish from each pond were randomly collected and anesthetised with an overdose (70mg/L) of MS 222 (Syndel, CO, USA). Final BL, BW and whole length (WL) were measured prior to blood sampling, and SGR $\left(\% \mathrm{~d}^{-1}\right)$ was calculated: SGR $=[(\ln$ final weight $-\ln$ initial weight)/rearing duration in days] $\times 100$. Blood was collected from caudal artery by sterile syringes and transferred into sterile tubes and centrifuged at $3.000 \mathrm{rpm}$ for $10 \mathrm{~min}$ at $4{ }^{\circ} \mathrm{C}$. The separated serum was transported to the laboratory under refrigeration and stored at $-80{ }^{\circ} \mathrm{C}$ prior to biochemical analysis.

Fish exterior surfaces were swabbed with $75 \%$ ethanol before the ventral midline was 
118 dissected. Faecal content was collected using sterile scalpel and forceps into a sterile tube by 119 squeezing along the exterior side of the intestine as described elsewhere (Li et al., 2014; Ye et al., 120 2014). Intestinal samples of 23 fish (group A, 7 fish; group B, 7 fish; group C, 5 fish; and group D, 4 fish) were immediately frozen in liquid nitrogen, transported to the laboratory and then stored at $-80{ }^{\circ} \mathrm{C}$ until DNA extraction. All samples were collected within $1 \mathrm{~h}$ post-fish capture.

The experiments were performed in accordance with the Regulations for the Administration of

Affairs Concerning Experimental Animals of China. The protocols applied in the present study were approved by the Institutional Animal Care and Use Committee of the Yangtze River

Fisheries Research Institute, Chinese Academy of Fishery Sciences (Approval ID: CAFSCJ2014-001).

\section{Blood biochemical parameters}

Frozen blood samples were first thawed at $-20{ }^{\circ} \mathrm{C}$ and then at $4{ }^{\circ} \mathrm{C}$ as described by Zhang et al.

130 (2010). Blood biochemical parameters, alanine aminotransferase (ALT), aspartate

aminotransferase (AST), alkaline phosphatase (ALP), total protein (TP), glucose (GLU),

triglyceride (TG), total cholesterol (TC), high-density lipoprotein cholesterol (HDL-C) and low-

Chemistry Analyzer using commercial kits (Olympus life and Material Science Europa GmbH,

D-20097 Hamburg, Germany) at Hubei Provincial Hospital of TCM.

\section{DNA extraction, PCR and sequencing}

137 For the analysis of bacterial diversity, $0.25 \mathrm{~g}$ (wet weight) of the intestinal samples was used to 
139

140

141

142

143

144

145

146

147

148

149

150

151

152

153

154

155

156

157

158

159

accordance with the manufacturer's protocols. The 338F (ACTCCTAC GGGAGGCAGCA) and 806R (GGACTACNNGGGTWTCTAAT) primers were used to amplify the bacterial 16S rRNA gene V3-V4 fragments. PCR integrant and protocols were carried out as described by Gu et al. (2016): $95^{\circ} \mathrm{C}$ for $2 \mathrm{~min}$, followed by 27 cycles at $95^{\circ} \mathrm{C}$ for $30 \mathrm{~s}, 55^{\circ} \mathrm{C}$ for $30 \mathrm{~s}$, and $72^{\circ} \mathrm{C}$ for $45 \mathrm{~s}$ and a final extension at $72^{\circ} \mathrm{C}$ for $10 \mathrm{~min}, 10^{\circ} \mathrm{C}$ until halted by user.

The PCR products were separated by $2 \%$ agarose gel electrophoresis and negative controls were always performed to make sure there was no contamination. All bands of the desired size (approximately 468 bp) were purified using the AxyPrep DNA Gel Extraction Kit (Axygen Biosciences, Union City, CA, U.S.). Prior to sequencing, purified PCR products were quantified by Qubit@3.0 (Life Invitrogen) and every twenty-four amplicons whose barcodes were different were mixed equally. The pooled DNA product was used to construct Illumina Pair-End library following Illumina's genomic DNA library preparation procedure. Then the amplicon library was paired-end sequenced $(2 \times 250)$ on an Illumina MiSeq platform (Shanghai Majorbio BioPharm Technology and Lingen Biotechnology Co., Ltd.) according to the standard protocols.

\section{Process of sequencing data}

Trimmomatic and QIIME (version 1.17) was used to process and quality-filter the raw fastq files (Caporaso et al., 2010; Gu et al., 2016). Three criteria were followed: (i) reads were truncated at any site receiving an average quality score $<20$ over a $50 \mathrm{bp}$ sliding window, discarding the truncated reads that were shorter than $50 \mathrm{bp}$; (ii) Exact barcode matching, $<20 \%$ mismatches were allowed, and reads containing ambiguous characters were removed; (iii) only sequences that overlap by longer than $10 \mathrm{bp}$ were assembled according to their overlap sequence; (iv) adjust 
160 the sequence direction, the mismatch number of barcode is 0 , and the maximum primer

161 mismatch number is 2 (Sun et al. 2015). UPARSE was used to cluster operational taxonomic

162 units (OTUs) with 97\% similarity cutoff, and UCHIME was applied to identify and remove

163 chimeric sequences based on both mode reference database and de novo. The phylogenetic

164 affiliation analysis of each 16S rRNA gene sequence was introduced by RDP Classifier against

165 the SILVA (SSU115)16S rRNA database with a confidence threshold of 70\% (Schloss et al.,

166 2011; Westcott et al., 2015).

167 Statistical analysis

168 Rarefaction analysis based on treatment and technical replicates was performed after sequence

169 re-sampling using the Mothur program (version 1.30.1, http://www.

170 mothur.org/wiki/Schloss_SOP\#Alpha_diversity). Alpha diversity indices were determined from

171 rarefied tables using the Shannon - Wiener index and Simpson index for species diversity and

172 the Chao1 index for species richness to reveal changes in intestinal microbiota in different

173 samples (Caporaso et al., 2011). The unweighted pair-group method based on Bray - Curtis

174 dissimilarity was used to perform a hierarchical clustering of different samples. Taxonomic

175 composition-based non-metric multidimensional scaling analysis and weighted UniFrac distance-

176 based PCoA analysis were conducted to illustrate the overall patterns of microbial communities

177 in the different samples. Multiple regression of environmental variables with the microbial

178 community groups was analysed. Independent regression models of genus taxonomy and

179 biochemical parameters were established to screen the microbial genera that could significantly

180 predict metabolic characters and to explore the potential relationships between intestinal 
181

182 183

microbes and host metabolism. Regression analysis was run on the entire dataset, and only significant differences were shown. Moreover, functional predictions on family-level microbiome were also performed in PICRUSt. All data were expressed as mean \pm SD. Twotailed Student's t-test was used to assess fish growth parameters and metabolic differences, and false discovery rate correction (Benjamini-Hochberg) was considered. Multivariate ANOVA was used to assess the differences in bighead carp intestinal bacterial communities between the different treatments. Statistical analyses were performed with the software SPSS 22.0 (IBM, New York, NY, USA) and R (ver. 3.0.1) package. The level of significance was set at a P value of $<0.05$.

\section{Accession number}

The data sets supporting the results of the article are available in the NCBI Sequence Read Archive under Accession No. SRS2374735.

\section{RESULTS}

\section{Growth performance and biochemical parameters}

Feed application significantly affected fish growth and SGR. The SGRs of bighead carp were significantly higher $(P<0.01)$ in groups $\mathrm{B}, \mathrm{C}$ and $\mathrm{D}$ than that in group $\mathrm{A}$, whereas the survival rate showed no difference among the treatments (Table 1).

Biochemical blood parameters, means and SD are shown in Table 2. The concentrations of ALT and LDL-C were significantly lower $(P<0.01)$ in groups A, B and C than in group D. TP, TC, TG, GLU and HDL-C were significantly $(P<0.01)$ lower in group A compared to the other groups. No significant $(P>0.05)$ differences in ALP and AST levels were noticed among the 
202

203

204

205

206

207

208

209

210

211

212

213

214

215

216

217

218

219

220

221

222

different treatments.

\section{Intestinal microbiota diversity and richness}

After quality filtering and length trimming, 759,048 high-quality bacterial sequences were obtained, equivalent to an average of 33,002 ( $\min 26,755$ and $\max 38,788$ ) reads per sample, when representative OTU sequences were classified using the RDP classifier.

The number of OTUs was analysed for each sample with a 97\% sequence similarity cut off value. Alpha diversity metrics showed no significant $(P>0.05)$ differences in OTU richness (Chao1 index) among the treatments (Fig. 1). Meanwhile, the Shannon - Wiener and Simpson indices significantly differed $(P<0.05)$ among the feeding strategies (Fig. 2). Group A and B had the highest diversity; significantly $(P<0.05)$ different from groups $\mathrm{C}$ and $\mathrm{D}$, By contrast, the diversities between groups $\mathrm{A}$ and $\mathrm{B}$ or between groups $\mathrm{C}$ and $\mathrm{D}$ revealed no significant $(P>0.05)$ difference.

\section{Intestinal microbiota composition}

Phyla Bacteroidetes, Fusobacteria, Firmicutes and Proteobacteria were dominant in group A (Fig. 3A). In group B, phyla Proteobacteria and Fusobacteria dominated the intestinal microbiome and constituted of $60.0 \% \pm 25.3 \%$ and $18.5 \% \pm 20.4 \%$, respectively, followed by Cyanobacteria, Bacteroidetes and Firmicutes. Phylum Proteobacteria was dominant in the intestinal microbiomes of group $C(96.1 \% \pm 2.5 \%)$ and group $\mathrm{D}(94.5 \% \pm 6.3 \%)$, whereas other phyla comprised $<2 \%$ of the total reads.

Figure $3 \mathrm{~B}$ revealed that, family Porphyromonadaceae $(40.2 \pm 22.3 \%)$, Fusobacteriaceae $(29.7 \pm 23.3 \%)$ and Peptostreptococcaceae $(12.2 \pm 7.6 \%)$ dominated the intestinal microbiome of 
223 group A. Family Gammaproteobacteria_unclassified OTU (31.6 \pm 26.7\%), Fusobacteriaceae

$224(18.8 \pm 27.8 \%)$, Aeromonadaceae $(14.6 \pm 13.5 \%)$ and Rhodocyclaceae $(4.85 \pm 4.70 \%)$

225 dominated the intestinal microbiome in group B. In group C and D, family Gammaproteobacteria

226 unclassified OTU were the dominant intestinal microbiome, with a portion of $85.3 \pm 11.7 \%$ and

$22783.0 \pm 17.0 \%$ of total reads, respectively. At the genus level, significant $(P<0.01)$ differences

228 were revealed among the treatments. The abundance of Cetobacterium (phylum Fusobacteria,

229 family Fusobacteriaceae), Peptostreptococcaceae_incertae_sedis OTU (phylum Firmicutes,

230 family Peptostreptococcaceae) and Porphyromonadaceae _uncultured OTU (phylum

231 Bacteroidetes, family Porphyromonadaceae) were significantly $(P<0.05)$ higher in group A

232 when compared to the three other groups. The genera Gammaproteobacteria_unclassified OTU

233 (phylum Proteobacteria), Aeromonas and Pseudomonas (phylum Proteobacteria, family

234 Aeromonadaceae and Pseudomonadaceae, respectively) and the genus Cetobacterium were

235 present at higher proportions in group B than in the other groups. The abundance of the genus

236 Aeromonas was significantly $(P<0.01)$ higher in group B than in group A, C and D. By contrast,

237 the genus Gammaproteobacteria_unclassified OTU was significantly higher $(P<0.01)$ in group C

238 and D than in the other groups (Table 3). Meanwhile, the shared taxa with relative abundance

239 above $1 \%$ were further examined to evaluate core bacterial shifts among different treatments.

240 Clear core bacterial turnover patterns among different treatments were visualised by the heat

241 maps, and no individual OTUs were shared across all diet combination treatments (Supporting

242 Information Fig. S2). 
244 Hierarchical clustering showed that bacterial communities clustered as a consequence of feeding

245 strategy treatments (Fig. 4). The microbiota community of group B dispersed: some clustered

246 with group A, while others clustered with groups C and D. A higher separation was revealed

247 between group A compared with groups C and D, as the two latter groups generally clustered

248 together.

\section{Functional analysis}

250 The relationships between genera and biochemical parameters were investigated separately

251 through independent regression models to explore the potential metabolic functions of the

252 intestinal microbiome in bighead carp. Genera Gammaproteobacteria_unclassified OTU,

253 Pseudomonas, Cetobacterium and Porphyromonadaceae_uncultured OTU were significantly

$254(P<0.05)$ related to the fish biochemical parameters (Fig. 5). Results showed that ALT and GLU

255 were positively associated with the genus Gammaproteobacteria_unclassified_OTU $\left(R^{2}=0.27\right.$

256 and $R^{2}=0.46$, respectively). By contrast, GLU was negatively associated with the genera

257 Cetobacterium and Porphyromonadaceae_uncultured OTU_( $R^{2}=0.24$ and $R^{2}=0.27$, respectively).

258 Moreover, AST was negatively correlated with the genus Pseudomonas, whereas TG was

259 positively correlated with the genus Pseudomonas $\left(R^{2}=0.72\right.$ and $R^{2}=0.79$, respectively).

\section{DISCUSSION}

261 Recently in China, the filter-feeding fish bighead carp has been successfully fed formulated feed

262 to increase the farm yield to meet the increasing demand (Mi et al., 2016). In the present study,

263 the SGR of group D was significantly $(P<0.05)$ higher than that in group A, and our results are

264 in accordance with Mi et al. (2016), suggesting feeding formulated feed could improve the 
265

266

267

268

269

270

271

272

273

274

275

276

277

278

279

280

281

282

283

284

285

growth rate of bighead carp. Though the survival rate is no significantly different between all treatments, $20-25 \%$ reduced survival existed in the group B, C and D, it may due to the poor condition of fish and lower dissolved oxygen in rainy day. In a previous study, Asadi et al. (2006) reported that ALT and AST are mainly located in the liver and reflect its physiological state. The significant $(P<0.05)$ increase in ALT activity in group D indicated a higher activity in the amino acid catabolism of the liver. The low GLU and TG in group A may be due to the placid behaviour of bighead carp under natural conditions, as bighead carp is more active to catch the formulated feed in groups B, C and D than in group A (Song \& Kong, 2013). These differences in catching food may induce more glycogen and protein catabolism, which affected the concentrations of GLU and TP (Atencio et al., 2005).

The gut microbial community of fish is modulated by dietary manipulations (Muegge et al., 2011; Wu et al., 2011; Ringø et al., 2016). However, to our knowledge, information about the intestinal microbiome of filter-feeding fish fed formulated feed is lacking. The results of present study improve the knowledge on the microbial communities of filter-feeding fish and feeding fish, and might be exploited in formulated feed production in the future. In general, fish intestinal microbiota is dominated mainly by the phyla Proteobacteria and Firmicutes (Navarrete et al., 2010; Sullam et al., 2012; Estruch et al., 2015; Miyake et al., 2015), while Fusobacteria was the dominant phylum in the current study, a finding which is in accordance with that revealed for common carp (Cyprinus carpio L.) (Van Kessel et al., 2011). Bacteroidetes is an abundant phyla in bighead carp (the present study), silver carp (Ye et al., 2014), paddle fish (Psephurus glades) (Li et al., 2014), sea bass (Dicentrarchus labrax) (Carda-Diéguez et al., 2014) and marine 
286 herbivorous fish (Sullam et al., 2012). Interestingly, the core intestinal microbial composition of

287 bighead carp in group A was more consistent with that previously reported in paddle fish that

288 similar dominant phyla Bacteroidetes, Fusobacteria, Firmicutes and Proteobacteria were revealed

289 (Li et al., 2014). This result may due to the fact that natural food consumed by paddle fish (Zhu

290 et al., 2014) is similar to that consumed by bighead carp in the present study.

291 In the present study, the intestinal microbial composition and community of bighead carp had

292 no relationships with the environmental variables (Supporting Information Table S2). However,

293 they were significantly influenced by the formulated feed; that is, bacterial community was

294 unique for groups A, C and D, whereas that for group B was variable (Fig. 3, Supporting

295 Information Fig. S1). Considering that more bacterial species and higher diversity of intestinal

296 microbiome were revealed in groups A and B than in other groups, we hypothesised that

297 formulated feed reduces the species and diversity of intestinal microbiome in bighead carp. The

298 variation in eaten natural food and its associated microbes may influence the gut bacteria

299 diversity because bighead carp is reportedly predominantly zooplanktivorous, and the fish may

eat phytoplankton and detritus when the concentrations of zooplankton are low (Zhang et al.,

2008). However, Bolnick et al. (2014) elucidated that multiple diet components can interact non-

additively to modulate the gut microbial diversity in three spine stickleback (Gasterosteus

aculeatus) and Eurasian perch (Perca fluviatilis). Moreover, despite the decreased diversity of 
307 bacterial diversity comparing with control group (Li et al. 2017). Whether fish growth

308 performance is related to intestinal microbial diversity merits further investigations.

309 In this study, genus Gammaproteobacteria_unclassified OTU substantially increased in 310 groups B, C and D and positively correlated with GLU and ALT concentrations, indicating that 311 this genus may be positively associated with carbohydrate and lipid metabolism. The 312 contribution of gastrointestinal microbiota to host carbohydrate and lipid metabolism has been 313 intensively studied in human, mice, cow and grass carp (Turnbaugh et al., 2006; Brulc et al., 314 2009; Velagapudi et al., 2010; Ni et al., 2014).

315 Previous studies have reported that Cetobacterium somerae is a common and widely 316 distributed species within the guts of freshwater fishes, and its prevalence is negatively 317 correlated with the dietary availability of vitamin $\mathrm{B}_{12}$ (Tsuchiya et al., 2008; Eichmiller et al., 318 2016). Hence, $C$. somerae has been assumed to have a main role in the synthesis of vitamin $\mathrm{B}_{12}$ 319 in the fish gut (Sugita \& Miyajima, 1991). However, as vitamin $\mathrm{B}_{12}$ within the natural food was 320 not investigated in the current study, further studies on this topic are needed. Supplementation of 321 vitamin $\mathrm{B}_{12}$ in formulated fish feed may lower the abundance of Cetobacterium in groups $\mathrm{C}$ and D. However, to verify this controversial hypothesis further studies are needed.In mice and human,

323 Porphyromonadaceae negatively affects lipid metabolism, and it is associated with non-alcoholic

324 fatty liver disease, atherosclerosis and diabetes in human (Henao-Mejia et al., 2012; Marques et 325 al., 2015), while Peptostreptococcaceae were revealed to be positively correlated with lipid 326 metabolism in bighead carp (Supporting Information Fig. S3). In addition, Cetobacterium and 327 Porphyromonadaceae_uncultured OTU, as the dominant genera in group A, were revealed to be 
328 negatively associated with GLU concentrations (Fig. 5), suggesting the fish GLU metabolism in

329 the fertiliser group may be limited by these bacteria. However, Fusobacteriaceae and

330 Peptostreptococcaceae both showed positive correlation with carbohydrate metabolism

331 (Supporting Information Fig. S3), more metagenomic sequencing and functional activity study of

332 intestinal microbiome in bighead carp are needed in the future.

333 In the current study, the genus Pseudomonas was negatively correlated with AST activity but

334 positively correlated with TG, suggests that Pseudomonas may be positively associated with

335 lipid metabolism. Family Pseudomonadaceae also showed a positive correlation with lipid

336 metabolism (Supporting Information Fig. S3). Considering that genus

337 Gammaproteobacteria_unclassified OTU and Pseudomonas were highly dominated in groups B,

$338 \mathrm{C}$ and D and both bacteria were positively related to lipid metabolism, we assumed that intestinal

339 bacteria could enhance lipid metabolic activity for bighead carp fed formulated feed.

340 CONCLUSIONS

341 In summary, the remarkable effect of feeding strategies on the intestinal microbiota of bighead

342 carp highlight the need to determine how different feeding strategies modulate the intestinal

343 microbiota and how this modulation affect the host. Higher bacterial diversities were shown in

344 group A and B than in group C and D. The core intestinal microbiome in group A comprised the

phyla Bacteroidetes, Fusobacteria, Firmicutes and Proteobacteria, whereas phyla Proteobacteria and Fusobacteria dominated in group B and only phylum Proteobacteria in groups C and D. in the present study, we suggest that limited carbohydrate metabolism is presented in group A, 
349 while high lipid metabolic activity exists in groups B, C and D. However, the regulatory 350 mechanisms of intestinal microbiome on the metabolism of bighead carp using other techniques 351 and the suitable feed formula for bighead carp based on intestinal microbiota functions require 352 further elucidation. 


\section{ADDITIONAL INFORMATION AND DECLARATIONS}

354 Acknowledgements

355 We thank the graduate students Degao Xu, Fei Li, Haocheng Li and Jianwei Yao for their help

356 during sample collection and Yaowan fish farming for supporting this study.

357 Data Availability

358 The following information was supplied regarding data availability:

359 Sequence Read Archive database: SRS2374735.

360

361 
362

363

364

365

366

367

368

369

370

371

372

373

374

375

376

377

378

379

380

381

382

383

384

385

386

387

388

389

390

391

\section{REFERENCES}

Asadi F, Masoudifard M, Vajhi A, Lee K, Pourkabir M, Khazraeini P. 2006. Serum biochemical parameters of Acipenser persicus. Fish Physiology \& Biochemistry 32 (1):4347 DOI 10.1007/s10695-005-5738-0.

Atencio A, Edwards HMJr, Pesti G. 2005. Effects of vitamin $\mathrm{D}_{3}$ dietary supplementation of broiler breeder hens on the performance and bone abnormalities of the progeny. Poultry Science 84(7):1058-1068 DOI 10.1093/ps/84.7.1058.

Baldo L, Riera JL, Tooming-Klunderud A, Albà MM, Salzburger W. 2015. Gut microbiota dynamics during dietary shift in Eastern African cichlid fishes. PLOS ONE 10(5):e0127462 DOI 10.1371/journal.pone.0127462.

Blum HE. 2017. The human microbiome. Advances in Medical Sciences 62:414-420 DOI 10.1016/j.advms.2017.04.005.

Bolnick DI, Snowberg LK, Hirsch PE. 2014. Individuals' diet diversity influences gut microbial diversity in two freshwater fish (threespine stickleback and Eurasian perch). Ecology Letters 17 (8):979-987 DOI 10.1111/ele.12301.

Brulc JM, Antonopoulos DA, Miller ME, Wilson MK, Yannarell AC, Dinsdale EA, Edwards RE, Frank ED, Emerson JB, Wacklin P, Coutinho PM, Henrissat B, Nelson KE, White BA. 2009. Gene-centric metagenomics of the fiber-adherent bovine rumen microbiome reveals forage specific glycoside hydrolases. Proceedings of the National Academy of Sciences USA 106(6):1948-1953 DOI 10.1073/pnas.0806191105.

Burke JS, Bayne DR, Rea H. 1986. Impact of silver and bighead carps on plankton communities of channel catfish ponds. Aquaculture 55(1):59-68.

Caporaso JG, Kuczynski J, Stombaugh J, Bittinger K, Bushman FD, Costello EK, Fierer N, Peña AG, Goodrich JK, Gordon JI, Huttley GA, Kelley ST, Knights D, Koenig JE, Ley RE, Lozupone CA, McDonald D, Muegge BD, Pirrung M, Reeder J, Sevinsky JR, Turnbaugh PJ, Walters WA, Widmann J, Yatsunenko T, Zaneveld J, Knight R. 2010. QIIME allows analysis of high-throughput community sequencing data. Nature Methods 7(5):335-336 DOI 10.1038/nmeth.f.303

Caporaso JG, Lauber CL, Walters WA, Berg-Lyons D, Lozupone CA, Turnbaugh PJ, Fierer N, Knight R. 2011. Global patterns of 16S rRNA diversity at a depth of millions of 
392

393

394

395

396

397

398

399

400

401

402

403

404

405

406

407

408

409

410

411

412

413

414

415

416

417

418

419

420

421

422

sequences per sample. Proceedings of the National Academy of Sciences USA 108(Supplement_1):4516-4522 DOI 10.1038/nmeth.f.303.

Carda-Diéguez M, Mira A, Fouz B. 2014. Pyrosequencing survey of intestinal microbiota diversity in cultured sea bass (Dicentrarchus labrax) fed functional diets. FEMS Microbiology Ecology 87(2):451-459 DOI 10.1111/1574- 6941.12236.

Conover G, Simmonds R, Whalen M. 2007. Management and control plan for bighead, black, grass, and silver carps in the United States. Asian Carp Working Group, Aquatic Nuisance Species Task Force, Washington, D.C.

Dinan TG, Cryan JF. 2017. Brain-gut-microbiota axis and mental health. Psychosomatic Medicine 79(8):920-926 DOI 10.1097/PSY.0000000000000519.

Eichmiller JJ, Hamilton MJ, Staley C, Sadowsky MJ, Sorensen PW. 2016. Environment shapes the fecal microbiome of invasive carp species. Microbiome 4(1):44 DOI 10.1186/s40168-016-0190-1.

Estruch G, Collado MC, Peñaranda DS, Tomás Vidal A, Jover Cerdá M, Pérez Martínez G, Martinez-Llorens S. 2015. Impact of fishmeal replacement in diets for gilthead sea bream (Sparus aurata) on the gastrointestinal microbiota determined by pyrosequencing the 16S rRNA gene. PLOS ONE 10(8):e0136389 DOI 10.1371/journal.pone.0136389.

FishBase. 2017. http://www.fishbase.org/search.php

Food and Agriculture Organization of the United Nations (FAO). 2015. Global aquaculture production.

Ghanbari M, Kneifel W, Domig KJ. 2015. A new view of the fish gut microbiome: advances from next-generation sequencing. Aquaculture 448:464-475 DOI 10.1016/j.aquaculture.2015.06.033.

Gu C, Yang Y, Xiang H, Li S, Liang L, Sui H, Zhan L, Lu X. 2016. Deciphering bacterial community changes in zucker diabetic fatty rats based on 16S rRNA gene sequences analysis. Oncotarget 7(31):48941-48952 DOI 10.18632/oncotarget. 10597.

Henao-Mejia J, Elinav E, Jin C, Hao L, Mehal WZ, Strowig T, Thaiss CA, Kau AL, Eisenbarth SC, Jurczak MJ, Camporez JP, Shulman GI, Gordon JI, Hoffman HM, Flavell RA. 2012. Inflammasome-mediated dysbiosis regulates progression of NAFLD and obesity. Nature 482(7384):179-185 DOI 10.1038/nature10809.

Huang AH, Pan DX. 2013. The technology of breeding bighead with compound feed. Fishery 
423

424

425

426

427

428

429

430

431

432

433

434

435

436

437

438

439

440

441

442

443

444

445

446

447

448

449

450

451

452

453

Guide to be Rich 6:33-34

Jiang XZ, Du NS. 1979. Chinese journal of animals (freshwater Cladocera). Science Press, Beijing.

Lazareva LP, Omarov MO, Lezina AN. 1977. Feeding and growth of the bighead, Aristichthys nobilis, in the waters of Dagestan. Journal of Applied Ichthyology 17:65-71

Ley RE, Lozupone CA, Hamady M, Knight R, Gordon JI. 2008. Worlds within worlds: evolution of the vertebrate gut microbiota. Nature Reviews Microbiology 6(10):776-788 DOI 10.1038/nrmicro1978.

Li FC, Wang JQ, Huang LB, Chen HJ, Wang CY. 2017. Effects of adding Clostridium sp. WJ06 on intestinal morphology and microbial diversity of growing pigs fed with natural deoxynivalenol contaminated wheat. Toxins 9(12): 383 DOI 10.3390/toxins9120383.

Li XM, Yu YH, Feng WS, Yan QY, Gong YC. 2012. Host species as a strong determinant of the intestinal microbiota of fish larvae. Journal of Microbiology 50(1):29-37 DOI 10.1007/s12275-012-1340-1.

Li XM, Yan QY, Xie SQ, Hu W, Yu YH, Hu ZH. 2013. Gut microbiota contributes to the growth of fast growing transgenic common carp (Cyprinus carpio L.). PLOS ONE 8(5):e64577 DOI 10.1371/journal. pone.0064577.

Li XM, Zhu YJ, Yan QY, Ringø E, Yang DG. 2014. Do the intestinal microbiotas differ between paddlefish (Polyodon spathala) and bighead carp (Aristichthys nobilis) reared in the same pond? Journal of Applied Microbiology 117(5):1245-1252 DOI 10.1111/jam.12626.

Li XM, Yan QY, Ringø E, Wu XB, He YF, Yang DG. 2016. The influence of weight and gender on intestinal bacterial community of wild largemouth bronze gudgeon (Coreius guichenoti, 1874). BMC Microbiology 16(1):191_DOI 10.1186/s12866-016-0809-1.

Marques TM, Wall R, O'Sullivan O, Fitzgerald GF, Shanahan F, Quigley EM, Cotter PD, Cryan JF, Dinan TG, Ross RP, Stanton C. 2015. Dietary trans-10, cis-12- conjugated linoleic acid alters fatty acid metabolism and microbiota composition in mice. British Journal of Nutrition 113(5):728-738 DOI 10.1017/S0007114514004206.

Merrifield DL, Bradley G, Harper GM, Baker RTM, Munn CB, Davies SJ. 2011. Assessment of the effects of vegetative and lyophilized Pediococcus acidilactici on growth, feed utilization, intestinal colonization, and health parameters of rainbow trout 
454

455

456

457

458

459

460

461

462

463

464

465

466

467

468

469

470

471

472

473

474

475

476

477

478

479

480

481

482

483

484

(Oncorhynchus mykiss Walbaum). Aquaculture Nutrition 17(1):73-79 DOI 10.1111/j.13652095.2009.00712.x.

Mi HF, Wen YH, Ge XP. 2016. The aquaculture situation and development trend of bighead carp in the Pearl River Delta. Scientific Fish Farming 10:82-84.

Miyake S, Ngugi DK, Stingl U. 2015. Diet strongly influences the gut microbiota of surgeonfishes. Molecular Ecology 24(3):656-72 DOI 10.1111/mec.13050.

Muegge BD, Kuczynski J, Knights D, Clemente JC, González A, Fontana L, Henrissat B, Knight R, Gordon JI. 2011. Diet drives convergence in gut microbiome functions across mammalian phylogeny and within humans. Science 332(6032):970-974 DOI 10.1126/science.1198719.

Navarrete P, Magne F, Mardones P, Riveros M, Opazo R, Suau A, Pochart P, Romero J. 2010. Molecular analysis of intestinal microbiota of rainbow trout (Oncorhynchus mykiss). FEMS Microbiology Ecology 71(1):148-156 DOI 10.1111/j.1574- 6941.2009.00769.x.

Nayak SK. 2010. Role of gastrointestinal microbiota in fish. Aquaculture Research 41(11):15531573 DOI10.1111/j.1365-2109.2010.02546.x. Ni JJ, Yan QY, Yu YH, Zhang TL. 2014. Factors influencing the grass carp gut microbiome and its effect on metabolism. FEMS Microbiology Ecology 87(3):704-714 DOI 10.1111/1574-6941.12256.

Pérez T, Balcázar JL, Ruiz-Zarzuela I, Halaihel N, Vendrell D, de Blas I, Múzquiz JL. 2010. Host-microbiota interactions within the fish intestinal ecosystem. Mucosal Immunology 3(4):355-360 DOI 10.1038/mi.2010.12.

Ray AK, Ghosh K, Ringø E. 2012. Enzyme-producing bacteria isolated from fish gut: a review. Aquaculture Nutrition 18(5):465-492 DOI 10.1111/j.1365-2095. 2012.00943.x.

Ringø E, Zhou Z, Vecino J LG, Wadsworth S, Romero J, Krogdahl Å. 2016. Effect of dietary components on the gut microbiota of aquatic animals. A never-ending story? Aquaculture Nutrition 22(2):219-282 DOI 10.1111/anu.12346.

Savas S, Kubilay A, Basmaz N. 2005. Effect of bacterial load in feeds on intestinal microflora of seabream (Sparus aurata) larvae and juveniles. The Israeli journal of aquaculture Bamidgeh 57(1):3-9 DOI http://hdl.handle.net/10524/19127

Schloss PD, Westcott SL. 2011. Assessing and improving methods used in operational taxonomic unit-based approaches for 16S rRNA gene sequence analysis. Applied \& Environmental Microbiology 77(10):3219-3226 DOI 10.1128/ AEM.02810-10. 
485 Shen JR. 1979. Chinese journal of animals (freshwater copepods). Science Press, Beijing.

486 Song WM, Kong XY. 2013. Thinking from the phenomenon of bighead carp devouring the expanded pellet feed. Scientific Fish Farming 1:74

Sugita H, Miyajima C. 1991. The vitamin $B_{12}$-producing ability of the intestinal microflora of freshwater fish. Aquaculture 92(2-3):267-76 DOI 10.1016/0044-8486(91)90028-6.

Sullam KE, Essinger SD, Lozupone CA, O'Connor MP, Rosen GL, Knight R, Kilham SS, Russell JA. 2012. Environmental and ecological factors that shape the gut bacterial communities of fish: a meta-analysis. Molecular Ecology 21(13):3363-3378_DOI 10.1111/j.1365-294X. 2012.05552.X.

Sun Q, Li A, Li M, Hou B. 2015. Effect of $\mathrm{pH}$ on biodiesel production and the microbial structure of glucose-fed activated sludge. International Biodeterioration \& Biodegradation 104:224-230 DOI 10.18632/oncotarget.10597

Tsuchiya C, Sakata T, Sugita H. 2008. Novel ecological niche of Cetobacterium somerae, an anaerobic bacterium in the intestinal tracts of freshwater fish. Letters in Applied Microbiology 46(1):43-48DOI 10.1111/j.1472-765X. 2007.02258.x.

Tarnecki AM, Burgos FA, Ray CL, Arias CR. 2017. Fish intestinal microbiome: diversity and symbiosis unravelled by metagenomics. Journal of Applied Microbiology DOI 10.1111/jam.13415.

Turnbaugh PJ, Ley RE, Mahowald MA, Magrini V, Mardis ER, Gordon JI. 2006. An obesity-associated gut microbiome with increased capacity for energy harvest. Nature 444(7122):1027-1031 DOI 10.1038/nature05414.

Van Kessel MAHJ, Dutilh BE, Neveling K, Kwint MP, Veltman JA, Flik G, Jetten MS, Klaren PH, Op den Camp HJ. 2011. Pyrosequencing of 16S rRNA gene amplicons to study the microbiota in the gastrointestinal tract of carp (Cyprinus carpio L.). AMB Express 1:1-9 DOI 10.1186/2191-0855-1-41.

Velagapudi VR, Hezaveh R, Reigstad CS, Gopalacharyulu P, Yetukuri L, Islam S, Felin J, Perkins R, Borén J, Oresic M, Bäckhed F. 2010. The gut microbiota modulates host energy and lipid metabolism in mice. Journal of Lipid Research 51(5):1101-1112 DOI 10.1194/jlr.M002774.

Wang JJ. 1961. Chinese journal of freshwater rotifers. Science Press, Beijing.

Westcott SL, Schloss PD. 2015. De novo clustering methods outperform reference-based 
516

517

518

519

520

521

522

523

524

525

526

527

528

529

530

531

532

533

534

535

536

537

538

539

540

541

542

543

544

545

methods for assigning 16S rRNA gene sequences to operational taxonomic units. Peer $J$ 3(12):e1487 DOI 10.7717/peerj.1487.

Wong S, Rawls JF. 2012. Intestinal microbiota composition in fishes is influenced by host ecology and environment. Molecular Ecology 21(13):3100-3102 DOI 10. 1111/j.1365294X.2012.05646.x.

Wu GD, Chen J, Hoffmann C, Bittinger K, Chen YY, Keilbaugh SA, Bewtra M, Knights D, Walters WA, Knight R, Sinha R, Gilroy E, Gupta K, Baldassano R, Nessel L, Li H, Bushman FD, Lewis JD. 2011. Linking long-term dietary patterns with gut microbial enterotypes. Science 334(6052):105-108 DOI 10.1126 /science.1208344

Xie P, Liu JK. 2001. Practical success of biomanipulation using filter-feeding fish to control cyanobacteria blooms: a synthesis of decades of research and application in a subtropical hypereutrophic lake. The Scientific World Journal 1:337-356 DOI 10.1100/tsw.2001.67

Yu HX, Tang WQ, Li SF. 2010. Morphological changes of silver and bighead carp in the Yangtze River over the past 50 years. Zoological Research 31(6):651-656 DOI 10.3724/SP.J.1141.2010. 06651.

Ye L, Amberg J, Chapman D, Gaikowski M, Liu WT. 2014. Fish gut microbiota analysis differentiates physiology and behavior of invasive Asian carp and indigenous American fish. ISME Journal 8(3):541-551 DOI 10.1038/ ismej.2013.181.

Zhang H, Xie C, Li D, Xiong D, Liu H, Shang P. 2010. Haematological and blood biochemical characteristics of Glyptosternum maculatum (Siluriformes: Sisoridae) in Xizang (Tibet). Fish Physiology \& Biochemistry 36(3):797-801 DOI 10.1007/s10695-009-9354-2.

Zhang X, Xie P, Huang X. 2008. A review of nontraditional biomanipulation. The Scientific World Journal 8(1):1184-1196 DOI 10.1100/tsw.2008.144

Zhong L, Li YG, Zhang ST. 1965. Fish biology and artificial breeding. Beijing: Science Press.

Zhou ZG, Ringø E, Olsen RE, Song SK. 2017. Dietary effects of soybean products on gut microbiota and immunity of aquatic animals: A review. Aquaculture Nutrition 24:644-665 DOI 10.1111/anu.12532.

Zhu YJ, Li XM, Yang DG. 2014. Do Food preference of paddlefish, Polyodon spathula (Walbaum, 1792), in polyculture with bighead carp Aristichthys nobilis (Richardson, 1845) in non-fed ponds. Journal of Applied Ichthyology 30(6):1596-1601 DOI 10.1111/jai.12590. 
547 Figure 1. Rarefaction analysis of MiSeq sequencing reads of the 16S rRNA gene in different fish 548 samples with different treatments. Rarefaction curves at a cutoff level of 3\% were constructed at 549 a 97\% sequence similarity cutoff value. A: fertiliser; B: fertiliser+1/2 feeding; C: fertiliser+ 550 feeding; D: feeding.

551

552 Figure 2. Alpha diversity Shannon (a) and Simpson (b) measures based on average operational 553 taxonomic units (OTUs) of fish with different treatments. Error bars indicate SD. *indicates $P<$ $5540.05 ; * *$ indicates $P<0.01$. A: fertiliser; B: fertiliser $+1 / 2$ feeding; C: fertiliser+ feeding; D: 555 feeding.

557 Figure 3. Distribution of average read number among the major phyla (a) and major class (b) in 558 fish intestinal microbiota with different treatments. A: fertiliser; B: fertiliser+1/2 feeding; C: 559 fertiliser+ feeding; D: feeding.

560

561 Figure 4. Unweighted pair-group method dendrograms showing the similarity of fish intestinal 562 microbiota with different treatments based on operational taxonomic units (OTUs). A: fertiliser; B: fertiliser+1/2 feeding; C: fertiliser+ feeding; D: feeding.

564

565

566

567

568

569

570

571

572

Figure 5. Scatter diagram (a-f) depicting the linear relationships of genus taxonomy and metabolic factors (all $P$ values $<0.05$ ). ALT, alanine transaminase; GLU, glucose; AST, aspartate aminotransferase; and TG, triglyceride. 
Figure 1

Rarefaction analysis of MiSeq sequencing reads of the 16S rRNA gene in different fish samples with different treatments.

Rarefaction curves at a cutoff level of $3 \%$ were constructed at a $97 \%$ sequence similarity cutoff value. A: fertiliser; B: fertiliser+1/2 feeding; C: fertiliser+ feeding; D: feeding. $E$

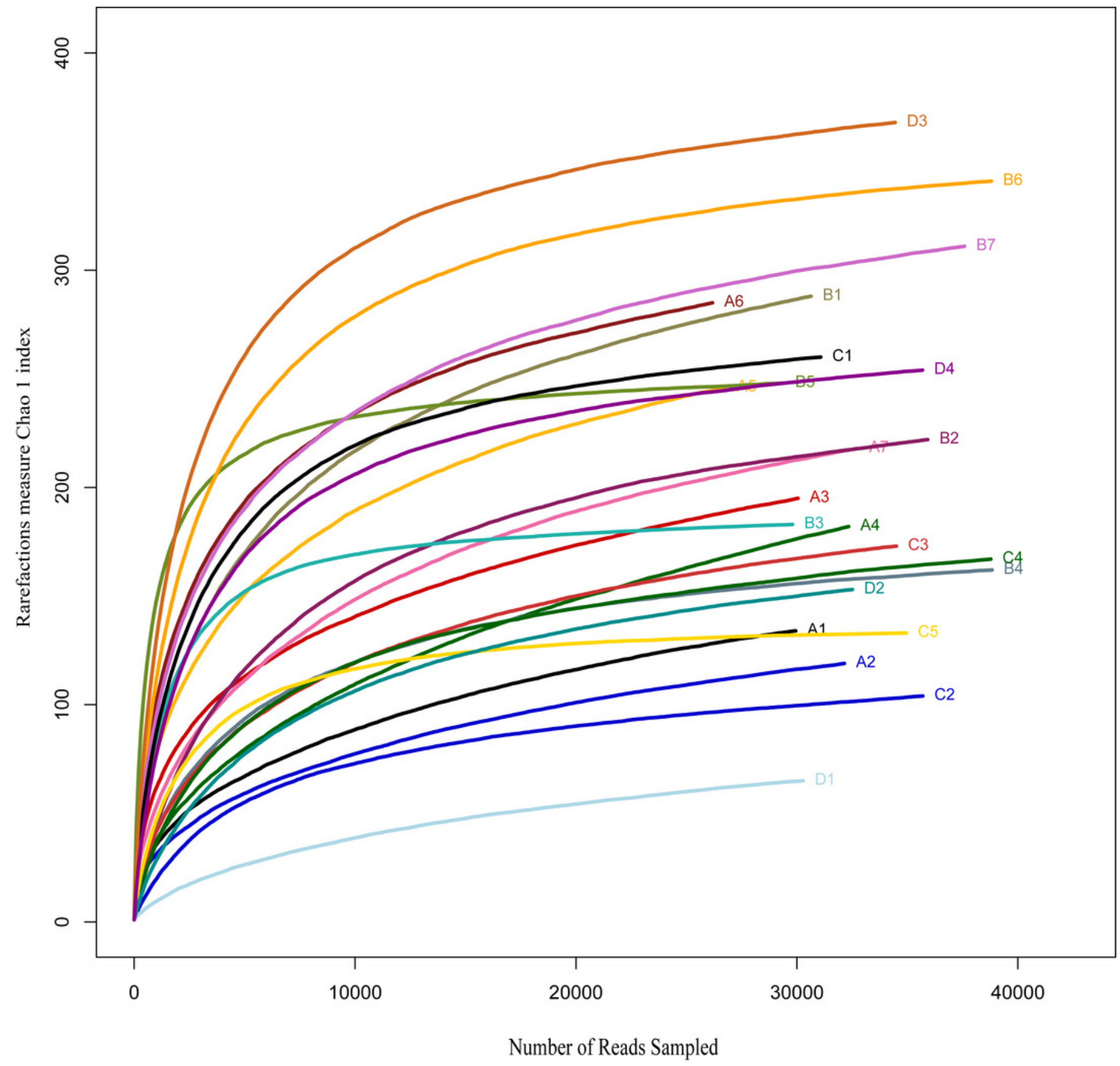


Figure 2

Alpha diversity Shannon (a) and Simpson (b) measures based on average operational taxonomic units (OTUs) of fish with different treatments

Error bars indicate SD. *indicates $P<0.05 ; * *$ indicates $P<0.01$. A: fertiliser; B: fertiliser $+1 / 2$ feeding; C: fertiliser+ feeding; D: feeding. 

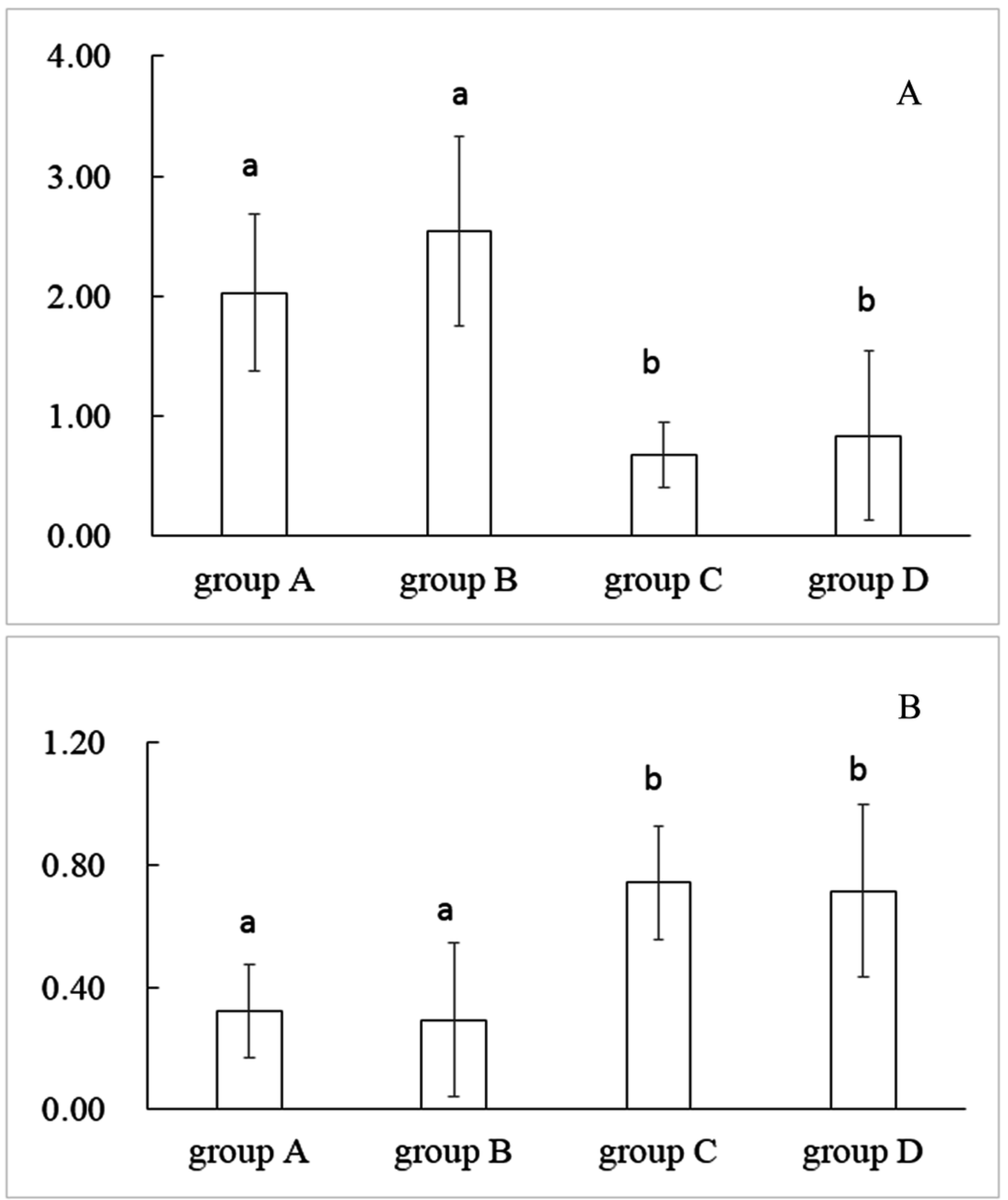
Figure 3

Distribution of average read number among the major phyla (a) and major class (b) in fish intestinal microbiota with different treatments.

A: fertiliser; B: fertiliser+1/2 feeding; C: fertiliser+ feeding; D: feeding. 

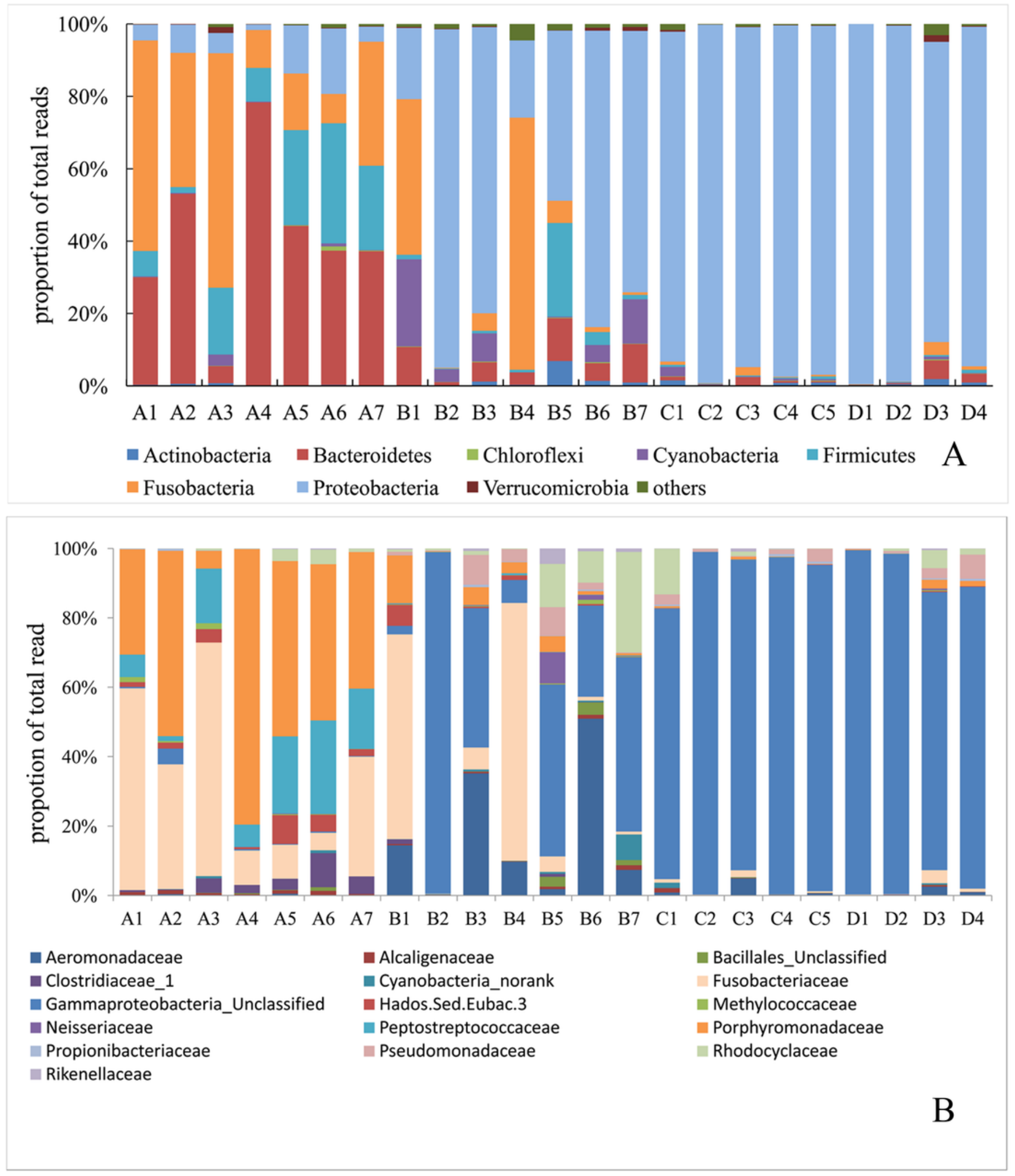


\section{Figure 4}

Unweighted pair-group method dendrograms showing the similarity of fish intestinal microbiota with different treatments based on operational taxonomic units (OTUs).

A: fertiliser; B: fertiliser+1/2 feeding; C: fertiliser+ feeding; D: feeding. 
$\square$ groupA

$\square$ groupB

- groupC

$\square$ groupD

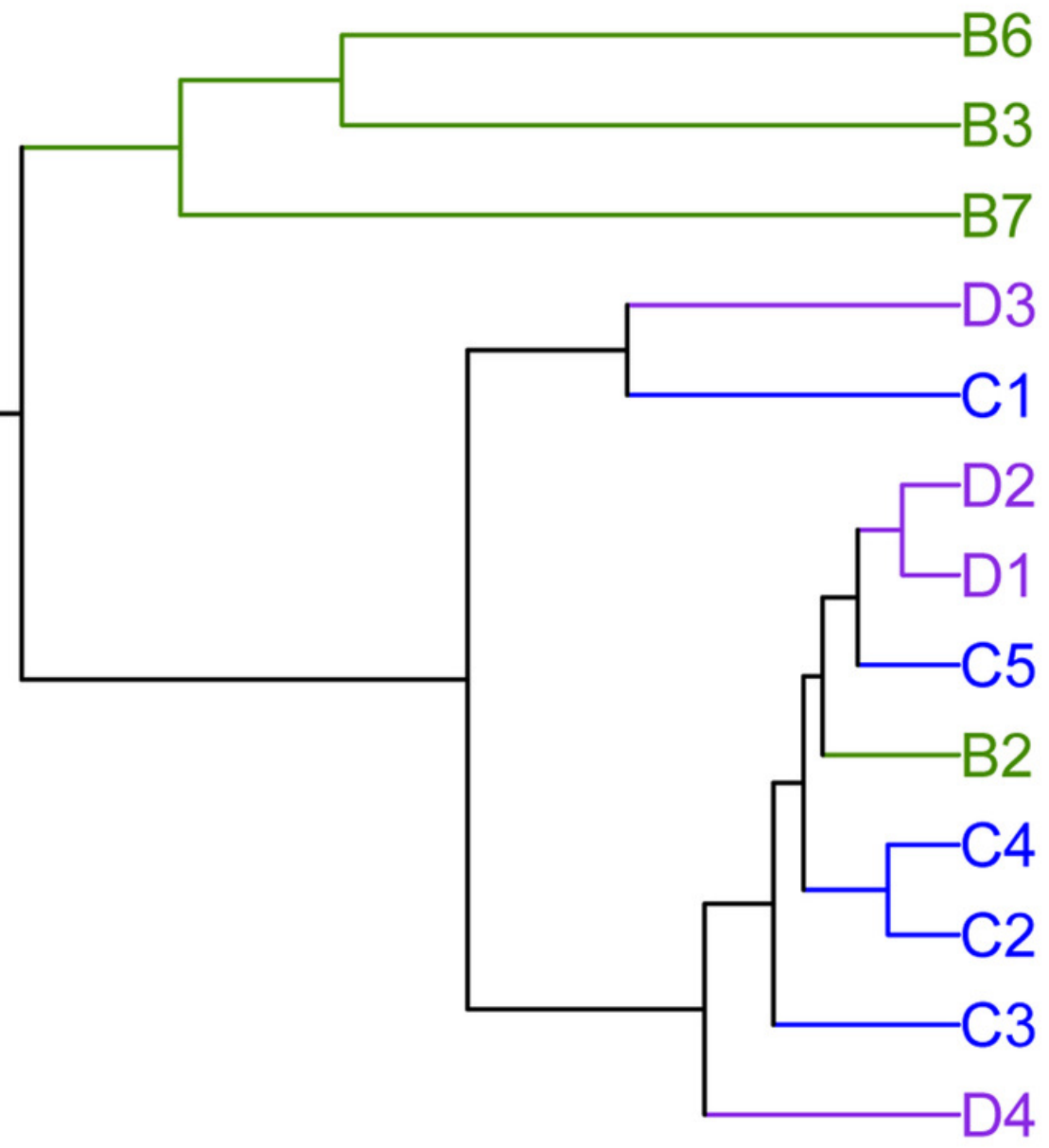

B5

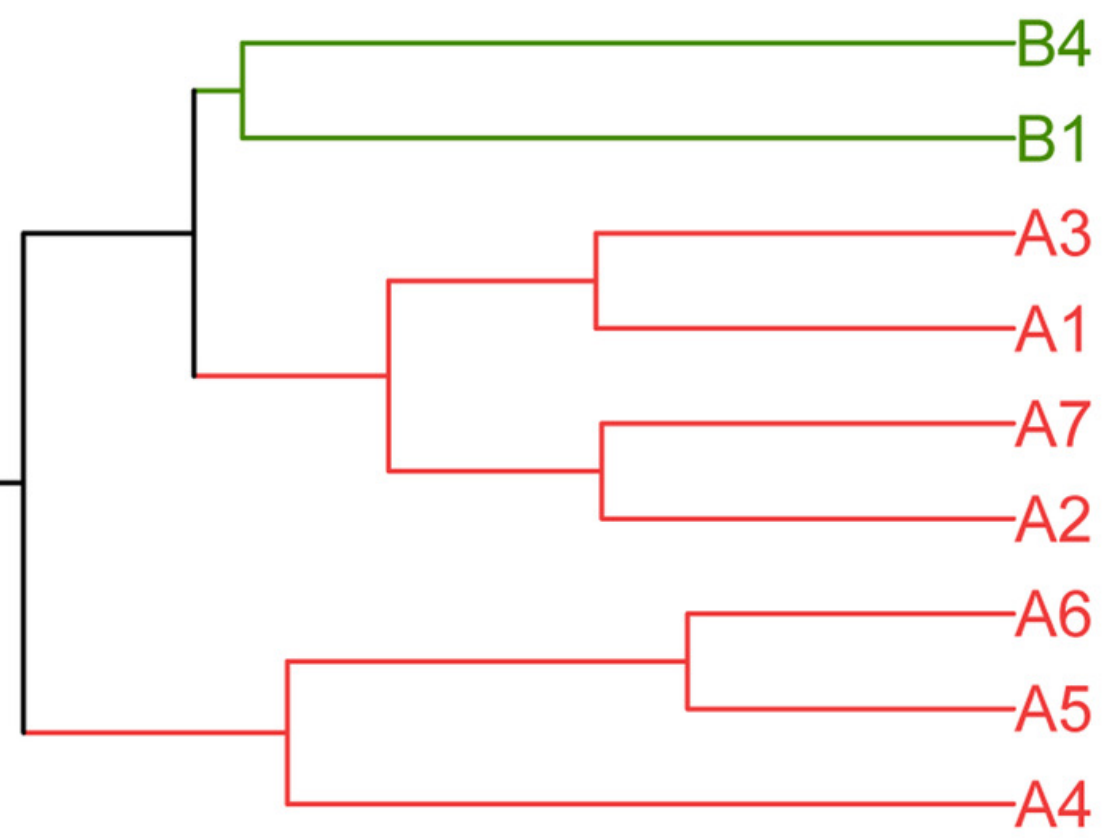

$\sqcup$

0.0 9 烏 reviewing PDF I (2018:05:28643:2:1:NEW 24 Oct 2018) 


\section{Figure 5}

Scatter diagram (a-f) depicting the linear relationships of genus taxonomy and metabolic factors (all $P$ values $<0.05$ ).

ALT, alanine transaminase; GLU, glucose; AST, aspartate aminotransferase; and TG, triglyceride. 

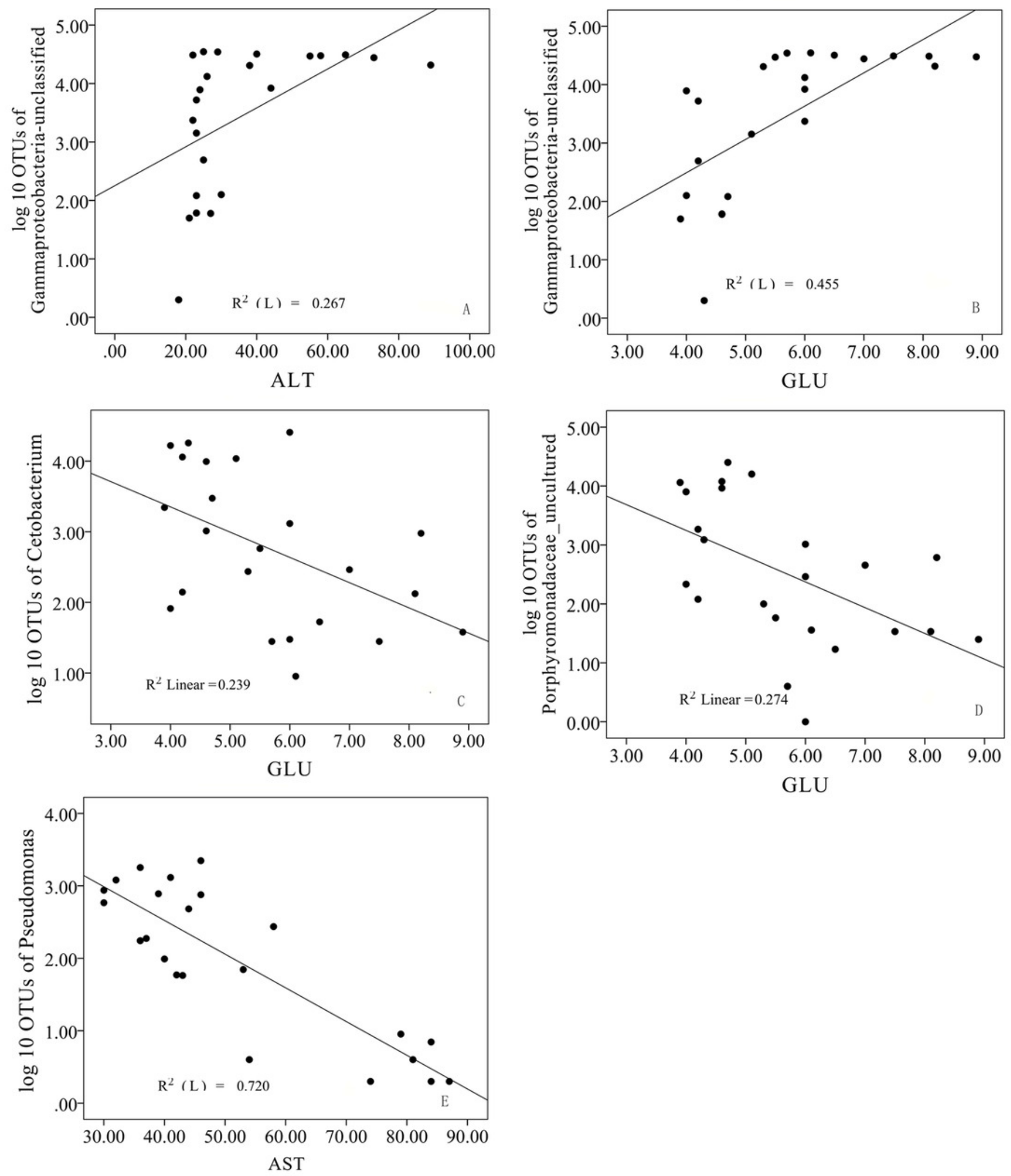


\section{Table $\mathbf{1}$ (on next page)}

Main growth performance of bighead carp in different treatments.

Mean \pm SD a,b,c indicates significant association $(P<0.05)$. 
1 Table 1. Main growth performance of bighead carp in different treatments. Mean $\pm \mathrm{SD}$

\begin{tabular}{|c|c|c|c|c|c|}
\hline & Group A & Group B & Group C & Group D & $P$ value \\
\hline Final weight (g) & $965.8 \pm 125.3^{\mathrm{a}}$ & $1233.6 \pm 343.9^{b c}$ & $1188.3 \pm 284.4^{b c}$ & $1426.6 \pm 159.0^{c}$ & $<0.01$ \\
\hline Survival (\%) & $96.0 \pm 5.20 \%$ & $70.8 \pm 30.2 \%$ & $75.0 \pm 10.5 \%$ & $70.8 \pm 10.5 \%$ & $\mathrm{NS}$ \\
\hline $\operatorname{SGR}\left(\% \mathrm{~d}^{-1}\right)$ & $0.04 \pm 0.03^{\mathrm{a}}$ & $0.17 \pm 0.16^{b}$ & $0.16 \pm 0.08^{b}$ & $0.25 \pm 0.06^{b}$ & $<0.01$ \\
\hline
\end{tabular}

2 a,b,c indicates significant association $(P<0.05)$.

3

4

5

6 


\section{Table 2 (on next page)}

Comparison of metabolic differences between fish groups under different treatments. Mean \pm SD

ALT, alanine transaminase; AST, aspartate aminotransferase; ALP, alkaline phosphatase; TP, total protein; TC, total cholesterol; TG, triglyceride; GLU, glucose; HDL-C, high-density lipoprotein; LDL-C, low-density lipoprotein; a,b,c indicates significant association $(P<0.05)$. 
1

2

Table 2. Comparison of metabolic differences between fish groups under different treatments. Mean \pm SD

\begin{tabular}{|c|c|c|c|c|c|}
\hline & Group A & Group B & Group C & Group D & $P$ value \\
\hline ALT(U/L) & $23.6 \pm 3.90^{\mathrm{a}}$ & $29.1 \pm 8.90^{\mathrm{a}}$ & $33.8 \pm 13.3^{\mathrm{a}}$ & $71.3 \pm 13.3^{b}$ & $<0.01$ \\
\hline AST(U/L) & $57.6 \pm 21.2$ & $36.7 \pm 5.20$ & $45.2 \pm 10.5$ & $42.5 \pm 4.70$ & NS \\
\hline ALP(U/L) & $32.0 \pm 19.3$ & $69.0 \pm 35.7$ & $70.4 \pm 25.1$ & $61.3 \pm 38.8$ & NS \\
\hline $\mathrm{TP}(\mathrm{g} / \mathrm{L})$ & $22.4 \pm 2.70^{\mathrm{a}}$ & $29.7 \pm 4.50^{b}$ & $29.5 \pm 1.90^{b}$ & $31.2 \pm 3.50^{b}$ & $<0.01$ \\
\hline $\mathrm{TC}(\mathrm{mmol} / \mathrm{L})$ & $1.80 \pm 0.40^{a}$ & $2.60 \pm 0.50^{b}$ & $2.70 \pm 0.40^{b}$ & $2.80 \pm 0.10^{b}$ & $<0.01$ \\
\hline TG (mmol/L) & $0.40 \pm 0.10^{\mathrm{a}}$ & $2.20 \pm 0.40^{\mathrm{b}}$ & $1.70 \pm 0.20^{\mathrm{c}}$ & $1.70 \pm 0.10^{\mathrm{c}}$ & $<0.01$ \\
\hline $\begin{array}{c}\text { GLU } \\
(\mathrm{mmol} / \mathrm{L})\end{array}$ & $4.50 \pm 0.40^{\mathrm{a}}$ & $5.30 \pm 1.10^{\mathrm{ab}}$ & $6.10 \pm 1.10^{b}$ & $7.90 \pm 0.80^{c}$ & $<0.01$ \\
\hline $\begin{array}{c}\text { HDL-C } \\
(\mathrm{mmol} / \mathrm{L})\end{array}$ & $0.20 \pm 0.10^{a}$ & $0.30 \pm 0.10^{b}$ & $0.30 \pm 0.10^{b c}$ & $0.4 \pm 0.10^{\mathrm{c}}$ & $<0.01$ \\
\hline $\begin{array}{c}\text { LDL-C } \\
(\mathrm{mmol} / \mathrm{L})\end{array}$ & $0.50 \pm 0.20^{a}$ & $0.60 \pm 0.10^{a b}$ & $0.06 \pm 0.20^{a b}$ & $0.80 \pm 0.10^{b}$ & $<0.05$ \\
\hline
\end{tabular}

3 ALT, alanine transaminase; AST, aspartate aminotransferase; ALP, alkaline phosphatase; TP, total 4 protein; TC, total cholesterol; TG, triglyceride; GLU, glucose; HDL-C, high-density lipoprotein; 5 LDL-C, low-density lipoprotein; a,b,c indicates significant association $(P<0.05)$.

6

7

8

9

10

11

12

13 


\section{Table 3 (on next page)}

Average relative abundances (\% of sequences per treatment) and standard deviation of the most abundant bacteria at the genus taxonomy level in fish intestine. Mean $\% \pm S D$ 
1

2 Table 3. Average relative abundances (\% of sequences per treatment) and standard deviation of

3 the most abundant bacteria at the genus taxonomy level in fish intestine. Mean $\% \pm \mathrm{SD}$

4

\begin{tabular}{|c|c|c|c|c|c|c|c|}
\hline Phylum & Family & Genus & Group A (\%) & Group B (\%) & Group C (\%) & Group D (\%) & $P$ value \\
\hline Proteobacteria & Aeromonadaceae & Aeromonas & $0.20 \pm 0.24^{\mathrm{a}}$ & $20.7 \pm 12.63^{b}$ & $1.38 \pm 1.10^{\mathrm{a}}$ & $0.98 \pm 1.23^{\mathrm{a}}$ & $<0.01$ \\
\hline Proteobacteria & & $\begin{array}{l}\text { Gammaproteobacteria_ } \\
\text { unclassified OTU }\end{array}$ & $0.95 \pm 0.76^{\mathrm{a}}$ & $50.3 \pm 38.9^{b}$ & $95.8 \pm 2.82^{c}$ & $93.8 \pm 6.31^{\mathrm{c}}$ & $<0.01$ \\
\hline Proteobacteria & Pseudomonadaceae & Pseudomonas & $0.02 \pm 0.01^{\mathrm{a}}$ & $4.39 \pm 3.02^{\mathrm{b}}$ & $1.93 \pm 1.62^{\mathrm{b}}$ & $2.78 \pm 1.22^{\mathrm{b}}$ & $<0.05$ \\
\hline Fusobacteria & Fusobacteriaceae & Cetobacterium & $34.5 \pm 27.3^{\mathrm{a}}$ & $21.8 \pm 4.12^{\mathrm{a}}$ & $0.72 \pm 0.79^{b}$ & $1.29 \pm 0.86^{\mathrm{b}}$ & $<0.05$ \\
\hline Firmicutes & Peptostreptococcaceae & $\begin{array}{l}\text { Peptostreptococcaceae } \\
\text { incertae_sedis OTU }\end{array}$ & $16.3 \pm 11.9^{\mathrm{a}}$ & $0.19 \pm 0.17^{b}$ & $0.08 \pm 0.04^{b}$ & $0.04 \pm 0.03^{b}$ & $<0.01$ \\
\hline \multirow[t]{2}{*}{ Bacteroidetes } & & $\begin{array}{l}\text { Porphyromonadaceae_ } \\
\text { uncultured OTU }\end{array}$ & $48.1 \pm 24.9^{a}$ & $2.61 \pm 1.82^{\mathrm{b}}$ & $0.17 \pm 0.17^{b}$ & $1.06 \pm 0.20^{\mathrm{b}}$ & $<0.01$ \\
\hline & Porphyromonadaceae & & & & & & \\
\hline
\end{tabular}

5 a,b,c indicates significant association $(P<0.05)$.

\section{6}

7

8

9

10

11

12

13

14

15

16

17

18

19

20

21

22 